Original Article

\title{
OPTIMIZATION OF ALBENDAZOLE 400 MG TABLET COMPRESSION PROCESS USING DESIGN OF EXPERIMENT (DOE) APPROACH
}

\author{
LUCAS PEDROSA D. A. SILVA, EMERSON MARIO BOLDO
}

Center of Medical and Pharmaceutical Sciences, State University of Western Parana, Cascavel, Parana, Brazil

Email: spedrosa.lucas@gmail.com

Received: 26 Nov 2020, Revised and Accepted: 29 Dec 2020

\begin{abstract}
Objective: The present study aims to model and optimize the compression process of the Albendazole 400 mg tablets of a pharmaceutical industry production line to increase the production speed (tablets $/ \mathrm{h}$ ) while maintaining quality requirements.

Methods: The study was conducted using the Design of Experiments (DoE) methodology to identify and correlate the critical parameters during the process that affect the maintenance of the compression speed. In order to support the experiments, was tested disintegration time, average hardness, hardness variation, average weight, and friability.

Results: Was obtained that quality attributes of disintegration and friability did not generate a significant model but it has been established correlations between Fill-O-Matic speed and main compression force in the responses of weight variation, hardness, and mean hardness. It was found that the main compression force between 6 to $9 \mathrm{kN}$, the pre-compression force of 1,965 to 5,615 kN, and the speed of 55 RPM for Fill-0-Matic speed are responsible for ensuring that all quality attributes analyzed remain within the expected specification.
\end{abstract}

Conclusion: It was possible to apply the Design of Experiment (DoE) methodology in the compression process of the drug Albendazole 400 mg and to evaluate the impact of the parameters of this step on the formation of the tablet to significantly increasing the productivity of this product. The Fill-O-Matic speed parameter was the main control factor discovered in this study to maintain quality attributes.

Keywords: Design of Experiment, Tablets, Press machine, Fill-O-Matic speed, Fette

(c) 2021 The Authors. Published by Innovare Academic Sciences Pvt Ltd. This is an open access article under the CC BY license (https://creativecommons.org/licenses/by/4.0/) DOI: https://dx.doi.org/10.22159/ijpps.2021v13i2.40382. Journal homepage: https://innovareacademics.in/journals/index.php/ijpps.

\section{INTRODUCTION}

The tablet is the most consumed and produced pharmaceutical form in the world. This fact is possibly justified by the greater chemical stability of the tablets when compared to other dosage forms. Besides that, they are more convenient to handle and are mostly administered orally. Also, tablets can be produced on a fast and extremely reproducible industrial scale, with highly controlled quality attributes [1].

The compression process used in the manufacture of tablets is given by the literal compression of a quantity of powder within the die cavity of a tablet press machine. The procedure is basically divided into 3 sub-steps: die cavity filling, tablet production with punches moving within the die, thereby compressing powder into the desired tablets (compression), and ejection of the tablet. Even though it looks like a simple process, today's tablet press machines provide a huge range of parameters in order to increase process control and, in turn, enable the production of tablets at a high speed $[1,2]$.

When evaluated individually, the compression stage has a direct influence on some quality attributes required for a tablet, such as disintegration and dissolution times, hardness, friability, and mean weight. Thus, a more detailed study on this process is justified to maintain the quality, safety, and efficacy of the medication, while not ignoring the pharmaceutical industry's constant search for increased productivity [2, 3].

However, during the development of a drug, it is common to focus more on defining the formulation than on the parameters to be used in unit operations. It is not uncommon to encounter problems when transferring technology (Scale-up), since the formulation is often defined on a laboratory scale and aiming to meet specific quality attributes while ignoring factors such as productivity. In addition to the fact that regulatory agencies are progressively increasing the requirements for registration and post-registration of medicines, the use of a statistical-based approach in the development or redevelopment of a product brings greater security and robustness to the production routine and reduces the need for any eventual change in the production process $[4,5]$.
In this context, agencies and institutions such as the Food and Drug Administration (FDA) and Internation Council for Harmonization (ICH), have been publishing guides and regulations that encourage the application of the Design of Experiments (DoE) concept and, using it, to implement the statistical methodology of response surface analysis, in order to provide the pharmaceutical industry with ways to obtain greater knowledge about their products, leading to the development of more robust and reproducible processes. In ICH 8, published in 2009, it is already possible to find information on design space or "workspace", where ranges of production parameters and/or characteristics of the raw material are tested, correlating them with impacts on quality attributes. In this way, it is possible to know which variations our process is capable of withstanding so that the finished product still remains approved in the quality control tests $[5,6]$.

The application of DoE is important to discover the individual and/or combined influence of the changed parameters. In recent years, there has been an increasing amount of literature showing the applicability of this statistical methodology in the pharmaceutical industry [7-11] and, more specifically, in the compression stage [1216]. In the work of Garlapati and Roi (2017), using statistical modeling, the authors were able to define the tablet press regulation parameters that best met the quality attributes of Levocetirizine tablet formulation [17]. Iancu et al. (2016) performed a similar series of experiments on Diclofenac Sodium orodispersible tablets to find the compression force that provided the best friability, disintegration time, wetting time, and hardness values [18].

Therefore, the purpose of this investigation was, using the Design of Experiment (DoE) methodology, to model and optimize the compression stage of the granulate produced by wet way of the Albendazole $400 \mathrm{mg}$ in the form of chewable tablets. Albendazole is the newest carbamate in the benzimidazole group. The drug is indicated mainly for intestinal nematodes and cestodes. Such a product has a global presence, being one of the most used drugs for the treatment of parasitic infections [19]. 
In a pharmaceutical industry located in southern Brazil, the compression stage of this antiparasitic is time-consuming. The maximum validated compressing speed is about $10 \mathrm{RPM}$. Assessing the productive records of this medicine, it was found that, during previous tests aiming at increasing the compression speed, problems arose such as the variation in weight and hardness, both exceeding the control and specification limits. This study, therefore, set out to assess the effect of compression phase parameters to increase the production speed (tablets/h) while maintaining quality requirements.

\section{MATERIALS AND METHODS}

\section{Experimental design}

Design-Expert version 7.1.3 software was used for the experimental design and statistical analysis [20]. Using ICH 8, 9, and 10 as a base, we have defined the following parameters for controlling the compression: Fill-O-Matic (FOM) Force Feeder Speed, PreCompression, and Main Compression forces. As response variables, the so-called quality attributes necessary for process control in the compression stage; the following attributes were used: Friability, Disintegration Time, Hardness, Relative Hardness Variation, and Weight Variation.

To assess the compression parameters influence on the response factors, we used an experimental $2^{3}$ complete factorial design (CFD) plus 3 central points, resulting in a total of 11 experiments. The ranges of the parameters as well as the response factors used for both experiments are shown in table 1. During the test, the compression speed was kept constant, at 63 RPM. The significance of the model and the tested factors were calculated using Analysis of Variance (ANOVA) statistical methodology with a significance level of $95 \%$ [21].

Table 1: Values of the parameters and response variables used in the compression stage

\begin{tabular}{lllll}
\hline Compression parameters & Ranges & & Quality attributes \\
\cline { 2 - 4 } & $\mathbf{- 1}$ & $\mathbf{0}$ & $\mathbf{1}$ & \\
\hline Fill-0-Matic Speed & $25 \mathrm{RPM}$ & $40 \mathrm{RPM}$ & $55 \mathrm{RPM}$ & Friability \\
Pre-compression Force & $1,965 \mathrm{kN}$ & $3,79 \mathrm{kN}$ & $5,615 \mathrm{kN}$ & Disintegration Time \\
Main Compression Force & $3,0 \mathrm{kN}$ & $6,5 \mathrm{kN}$ & $10 \mathrm{kN}$ & Hardness \\
& & & & Relative Hardness Variation \\
& & & Weight Variation & $<1,5 \%$ \\
\end{tabular}

(*) Brazilian Pharmacopoeia [22]

\section{Materials}

The inputs used were: Lactose (Friesland Campina DMV Bv), Talc (SKC Inc), Corn Starch (Cargill Agrícola SA), Saccharin Sodium (Tiankin North Food Co, Inc), Magnesium Stearate (Itacel Farmoquímica Inc), Microcrystalline Cellulose (Itacel Farmoquímica Inc), Sodium Amidoglycolate (Itacel Farmoquímica Inc), Povidone 30 (Ashland Speciality Ingredients), Croscarmellose Sodic (Itacel Farmoquímica Inc), Micronized Albendazole (Punjab Chemical and Crop Protection), Sodium Laurilsulfate (Volp Inc) and Aerosil (Evonik Degussa Brasil Inc). The necessary materials, as well as the equipment used to manufacture the tablets, were provided by the company. The proportions were omitted because it is an industrial secret.

\section{Dry mix}

The ingredients were weighed and then sieved using a $1.5 \mathrm{~mm}$ mesh sieve. The inputs, already sieved, were mixed in the High Shear Comasa RD edition for 4 min with the impeller at 80 RPM.

\section{Granulation}

The agglutinating solution for granulation was prepared by adding the inputs from that stage to the water under constant agitation of the mechanical stirrer (IKA RW 20) at 300 RPM. After the ingredients are completely dissolved, was added the prepared solution to the dough under mixing with the impeller at 80 RPM. At the end of the addition, the chipper was activated at 3000 RPM for 2 min to standardize the granulate formed.

\section{Drying}

Drying was carried out in the Comasa RD Developer fluidized bed. The inlet temperature used was $50{ }^{\circ} \mathrm{C}$. The process took about 40 min until the granules reach the desired humidity range, between $2.5-3.5 \%$.

\section{Calibration and external phase}

After drying, granulate was calibrated in a benchtop granulator at 300 RPM speed through a $1.0 \mathrm{~mm}$ mesh sieve. The preparation of the external phase was carried out in a benchtop mixer (Bin Mixer SaintyCo). The granulate was added to the Bin, followed by the inputs, except for magnesium stearate and colloidal silicon dioxide, previously sieved manually in a $1.0 \mathrm{~mm}$ mesh sieve. The mixing took place for $10 \mathrm{~min}$ at $8 \mathrm{RPM}$. Afterward, the lubricants sieved in a sieve with $0.5 \mathrm{~mm}$ mesh were added, mixing for $3 \mathrm{~min}$ at $8 \mathrm{RPM}$.

\section{Compression process}

The tablet compression took place in the Fette 102i tablet press machine using a rotor with 8 punches of $17 \times 7.5 \mathrm{~mm}$. The stage was started by adjusting the average tablet weight to $770 \mathrm{mg} \pm 5 \%$ and compression speed at 63 RPM. For each condition indicated in table 1 , all tablets formed within one minute were collected. The average weight was adjusted only at the beginning of the process; the compression parameters were adjusted independently and with the equipment stopped for each variable.

\section{Analysis of quality attributes}

Tests chosen to assess the impact of the compression parameters were all carried out based on the one described in the general methods of the Brazilian Pharmacopoeia [22].

\section{Friability}

Friability analysis was executed with the weighing of 10 tablets by submitting them to the Erweka TAR 120/220 friabilometer for $4 \mathrm{~min}$ at 25 RPM.

\section{Disintegration time}

An Erweka ZT 320 disintegrator was used for this test. The water used as the immersion liquid was kept at $37 \pm 1{ }^{\circ} \mathrm{C}$. Was used 6 pills in each vat and the time was recorded as soon as the last pill was completely disintegrated. The established time limit was $30 \mathrm{~min}$.

\section{Hardness and relative hardness variation}

This test was performed with an Erweka durometer model THB 125. The mean and the relative amplitude, calculated by the difference of the minimum and maximum hardness of 10 tablets was determined, in addition to the calculation of the relative standard deviation.

\section{Average weight and weight variation}

Were weighed 20 tablets, individually on the scale (Metler ToledoAL204) with subsequent calculation of the standard deviation. The specification recommended by the Pharmacopoeia is a variation of $\pm 10 \%$ in relation to the ideal average weight.

\section{RESULTS AND DISCUSSION}

Table 2 shows the order of the experiments as well as the results obtained for each response variable. Analyzing the results, one can affirm that, by the programmed compression parameters, was 
observed that there was an influence on the disintegration time. However, it was not possible the statistical correlation with the programmed parameters, a fact that was confirmed by the nonsignificance of the model, indicated by the p-value greater than 0.05 . In this test, the evaluated tablets took an average of $395 \mathrm{~s}$ for complete disintegration, with values of a minimum of $309 \mathrm{~s}$ and a maximum of $456 \mathrm{~s}$. Such results are within the recommended by the Brazilian Pharmacopoeia, which specifies that the tablets should not take more than $1800 \mathrm{~s}$ to disintegrate [22]. The model's nonsignificance was attributed mainly to two factors. First, the presence of sodium lauryl sulfate in the formulation, which has the function of increasing the active ingredient wettability, which in turn can lead to a lower disintegration time regardless of the hardness obtained. Second, the pre-compression and main compression force ranges may not have been wide enough to demonstrate a significant variation in the test [23].

Table 2: Complete factorial experimental design with 3 factors in 2 levels with 3 central points, as well as the results obtained for each response variable

\begin{tabular}{|c|c|c|c|c|c|c|c|c|}
\hline Run & MCF (kN) & SFOM (RPM) & PCF (kN) & DES (s) & RHV (\%) & FRI (\%) & HAR (kp) & WV (mg) \\
\hline 1 & 6.5 & 40 & 3.79 & 369 & 0.169919 & 0.012 & 9.6 & 17.7291 \\
\hline 2 & 10 & 55 & 5.615 & 371 & 0.183783 & 0.049 & 15.6 & 17.99386 \\
\hline 3 & 3 & 25 & 5.615 & 456 & 0.30786 & 0.179 & 6.8 & 17.06729 \\
\hline 4 & 10 & 25 & 5.615 & 385 & 0.154417 & 0.01 & 15.35 & 22.42497 \\
\hline 5 & 6.5 & 40 & 3.79 & 427 & 0.191025 & 0.115 & 11.25 & 18.11983 \\
\hline 6 & 6.5 & 40 & 3.79 & 385 & 0.226189 & 0.095 & 11.25 & 18.56584 \\
\hline 7 & 3 & 55 & 1.965 & 427 & 0.12859 & 0.918 & 4.55 & 12.77506 \\
\hline 8 & 10 & 55 & 1.965 & 397 & 0.084606 & 0 & 16 & 10.49255 \\
\hline 9 & 3 & 25 & 1.965 & 309 & 0.278909 & 1.05 & 4.5 & 26.74043 \\
\hline 10 & 10 & 25 & 1.965 & 364 & 0.239973 & 0.075 & 14.8 & 20.03285 \\
\hline 11 & 3 & 55 & 5.615 & 452 & 0.135194 & 0.007 & 7.2 & 11.06578 \\
\hline
\end{tabular}

MCF = Main Compression Force, SFOM = FOM Speed, PCF = Pre-Compression Force, DES = Disintegration Time, RHV = Relative Hardness Variation, FRI $=$ Friability, HAR $=$ Hardness, WV $=$ Weight Variation .

The Friability response variable was impacted when the compression and pre-compression force parameters were changed. However, it was not possible to establish a statistical model to correlate the effects with the responses, since the p-value was above 0.05. According to Masilungan and Kraus (1989), the correlation between strength parameters and friability is explicit, indicating the role of increasing hardness, to a certain extent, in decreasing friability [24].

Looking at table 2, it is possible to argue that, at least empirically, when the main compression force of $10 \mathrm{kN}$ is exerted, the highest tested force, the average friability results are about 15 times lower when compared to that obtained using the lowest force, $3 \mathrm{kN}$. It is still possible to correlate the pre-compression force, because when applied at its highest tested value, $5.615 \mathrm{kN}$, there is also a positive impact on the friability values.

The Weight Variation variable (WV), on the other hand, was directly impacted by the Fill-O-Matic Speed factor (SFOM) and by the interaction of Fill-0-Matic Speed, Main Compression Force, and PreCompression Force factors.

The data obtained through the analysis of variance (table 3) for the Weight Variation attribute showed normal behavior, the residues are distributed randomly around zero and there are no outliers. The values are arranged within the acceptable range ( $3 \sigma$ to- $3 \sigma)$. The p-value of the model at 0.0020 and the F-value 83.28 , as well as the non-significance of the Lack of Fit, indicate the significance for a linear model.

Table 3: Analysis of variance (ANOVA) of the response variables, adopting a 95\% confidence level

\begin{tabular}{|c|c|c|c|c|c|c|}
\hline Hardness (kp) & SS & DF & MS & F Value & P-value prob $>F$ & $\mathbf{S}$ \\
\hline Model & 187.21125 & 1 & 187.21125 & 170.604 & $<0.0001$ & significant \\
\hline A-Main Compression & 187.21125 & 1 & 187.21125 & 170.604 & $<0.0001$ & \\
\hline Curvature & 0.021818182 & 1 & 0.021818182 & 0.019883 & 0.8914 & not significant \\
\hline Residual & 8.77875 & 8 & 1.09734375 & & & \\
\hline Lack of Fit & 6.96375 & 6 & 1.160625 & 1.278926 & 0.5008 & not significant \\
\hline Pure Error & 1.815 & 2 & 0.9075 & & & \\
\hline Cor Total & 196.0118182 & 10 & & & & \\
\hline \multicolumn{7}{|c|}{ Relative hardness variation (\%) } \\
\hline Model & 0.025198653 & 1 & 0.025198653 & 10.1339 & 0.0129 & significant \\
\hline B-FOM Speed & 0.025198653 & 1 & 0.025198653 & 10.1339 & 0.0129 & \\
\hline Curvature & $9.3453 \mathrm{E}-05$ & 1 & $9.3453 \mathrm{E}-05$ & 0.037583 & 0.8511 & not significant \\
\hline Residual & 0.019892563 & 8 & 0.00248657 & & & \\
\hline Lack of Fit & 0.018276507 & 6 & 0.003046084 & 3.769777 & 0.2245 & not significant \\
\hline Pure Error & 0.001616056 & 2 & 0.000808028 & & & \\
\hline Cor Total & 0.045184669 & 10 & & & & \\
\hline \multicolumn{7}{|l|}{ Weight variation (mg) } \\
\hline Model & 228.0499 & 6 & 38.00832 & 83.27746 & 0.0020 & significant \\
\hline A-Main Compression & 1.357678 & 1 & 1.357678 & 2.974716 & 0.1830 & \\
\hline B-FOM Speed & 143.9761 & 1 & 143.9761 & 315.4562 & 0.0004 & \\
\hline C-Pre-compression & 0.277136 & 1 & 0.277136 & 0.607215 & 0.4927 & \\
\hline $\mathrm{AB}$ & 4.493217 & 1 & 4.493217 & 9.844783 & 0.0518 & \\
\hline $\mathrm{AC}$ & 56.58272 & 1 & 56.58272 & 123.9745 & 0.0016 & \\
\hline $\mathrm{BC}$ & 21.36312 & 1 & 21.36312 & 46.80728 & 0.0064 & \\
\hline Curvature & 1.446227 & 1 & 1.446227 & 3.168729 & 0.1731 & not significant \\
\hline Residual & 1.369217 & 3 & 0.456406 & & & \\
\hline Lack of Fit & 1.018638 & 1 & 1.018638 & 5.811164 & 0.1375 & not significant \\
\hline Pure Error & 0.35058 & 2 & 0.17529 & & & \\
\hline Cor Total & 230.8654 & 10 & & & & \\
\hline
\end{tabular}

SS $=$ Sum of Squares, DF $=$ Degree of Freedom, MS = Mean Square, $\mathrm{S}=$ Significant 
In fig. 1, the effect of changing the Fill-0-Matic Speed and PreCompression force parameters on the Weight Variation response variable is demonstrated. The influence of FOM Speed on weight variation has already been mentioned in the literature. Some studies correlate the significance of this influence with the flow characteristics of the powder [25]. Free-flowing powders do not have a significant impact of the FOM Speed on quality attributes; however, for powders with less flow, the use of different speeds directly impacts quality attributes [26]. The drug chosen as a model for this study, Albendazole $400 \mathrm{mg}$, has the characteristic of a fine powder, even after granulation, since the active ingredient is micronized and is present in a large percentage in the formulation. Even not determining the flow properties, it is possible, visually, to assume that the material does not have a good/excellent flow.

The model also indicated interactions between the Main Compression Force and Pre-Compression Force. When increasing the Main Compression Force, the Weight Variation increases when $5.615 \mathrm{kN}$ of Pre-Compression force is applied. However, when the PreCompression force was $1.965 \mathrm{kN}$ the opposite effect was observed.

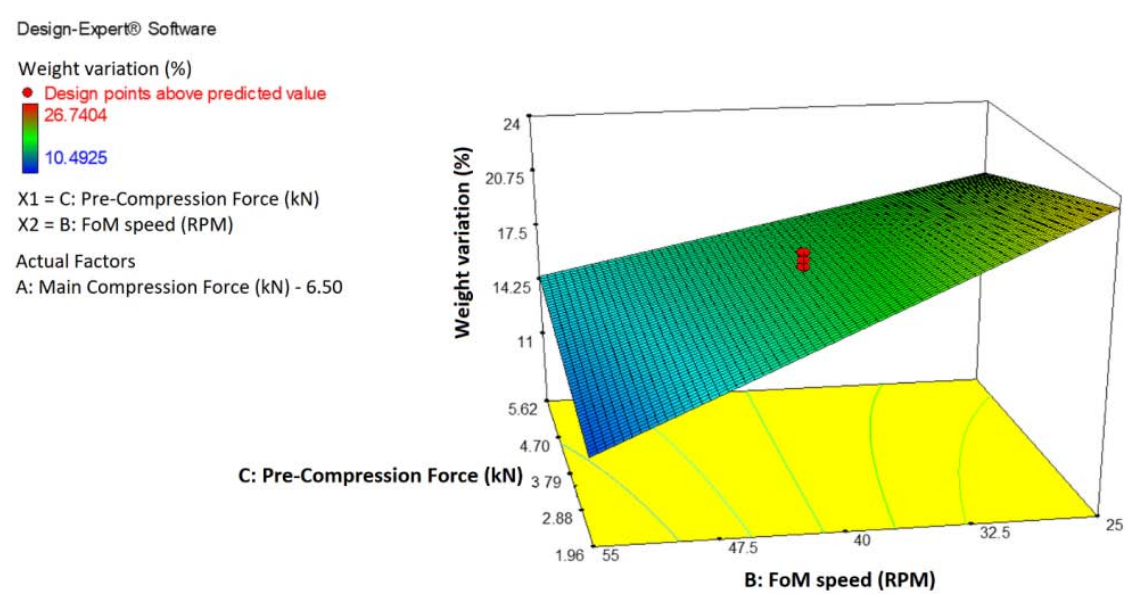

Fig. 1: Impact of changing the FOM speed factor on the response to weight variation

The interactions of other factors, such as the FOM Speed with the Pre-Compression force, do have an impact on the Weight Variation response variable, but they will not be considered in this discussion, due to the small influence they have on the effect, only $8.59 \%$ of the total. However, for the significance of the model, these factors were considered, as shown in the equation below.

Weight variation $=51.276-2.031 \mathrm{MCF}-0.602 \mathrm{SFOM}-$ $5.196 \mathrm{PCF}+0.0142$ (MCF)(SFOM)+0.416(MCF)(PCF)+0.059(SFOM)(MCF)

where MCF = Main Compression Force, $\mathrm{PCF}=$ Pre-Compression Force e SFOM = Fill-O-Matic Speed.

The variables of Hardness and Relative Hardness Variation were impacted by the Main Compression values chosen for the experimental design.

Hardness was impacted by the change in the Main Compression Force, having a positive effect; that is, according to the increase in the main compression force, the data obtained by the experiment (fig. 2) showed normal behavior. The residues are randomly distributed around from zero and there are also no outliers with values within the acceptable range $(3 \sigma$ to- $3 \sigma)$. The p-value of the model at 0.0001 and the F-value of 170.60, as well as the non-significance of the Lack of Fit, indicate the significance for a linear model.

It is possible to indicate the appropriate force range to comply with the specifications outlined in table 1 . According to fig. 2 , the force specification range should be between 6 at $9 \mathrm{kN}$ in the Main Compression Force and, regardless of the force exerted in the precompression phase, the resulting Hardness will be between 9-15 kp according to the model. This behavior is already easily found in the literature, where the greater the main compression force employed, the greater the resulting hardness. However, there is a breaking point where the tablet cannot increase the hardness any more regardless of the force used [27]

The equation that was provided by the model was represented below:

\section{Hardness $=1.616+1.382 \mathrm{MCP}$}

where: MCF = Main Compression Force.
Regarding the hardness variation, expressed by the Relative Hardness Variation response of each 20 tablets, it was possible during data analysis (table 3 ) to determine the negative relationship of the FOM Speed (fig. 2) in the hardness variation values. The higher the FOM Speed, the smaller the observed Hardness Variation, according to the model equation shown below.

\section{Hardness Variation $=0.339-3.741 \times 10^{-3} \mathrm{SFOM}$}

where: SFOM = Fill-0-Matic Speed

The data obtained showed normality and random distribution around the zero axes, the residues remained within the expected range of 3 to-3 standard deviations, added to the p-value of the model 0.0129 and the non-significance of the Lack of Fit, we assume that the model built is significant.

As can be seen from fig. 2, the FOM Speed significantly impacts the Relative Hardness Variation found. It can be established, therefore, that the 55 RPM FOM Speed is ideal within the values tested for the speed of 63 RPM of the tablet press rotor, since it presented lower values of weight variation as well as in hardness.

After all the experiments, it can be seen that regardless of the factors used, the Disintegration Time and Friability remained within that specified in table 1 . This way, the ranges used in this investigation can be applied during batch production. However, as already discussed, the variables Hardness, Relative Hardness Variation, and Weight Variation are impacted by the factors of Main Compression Force and/or FOM Speed.

At the end of this study, it can be verified that the ranges of the factors Main Compression Force of 6 to $9 \mathrm{kN}$, Pre-Compression Force of 1,965 to $5,615 \mathrm{kN}$, and $55 \mathrm{RPM}$ of FOM Speed, are responsible for all the attributes of analyzed qualities to remain within the specification expected. Comparing with other authors who carried out a similar investigation in the compression stage [12], it is observed that our study found some different results, mainly in the responses of Friability and Disintegration Time. As briefly discussed earlier, the force ranges used in this work, added to the intrinsic characteristics of our formulation, may have led to the behavior observed. 

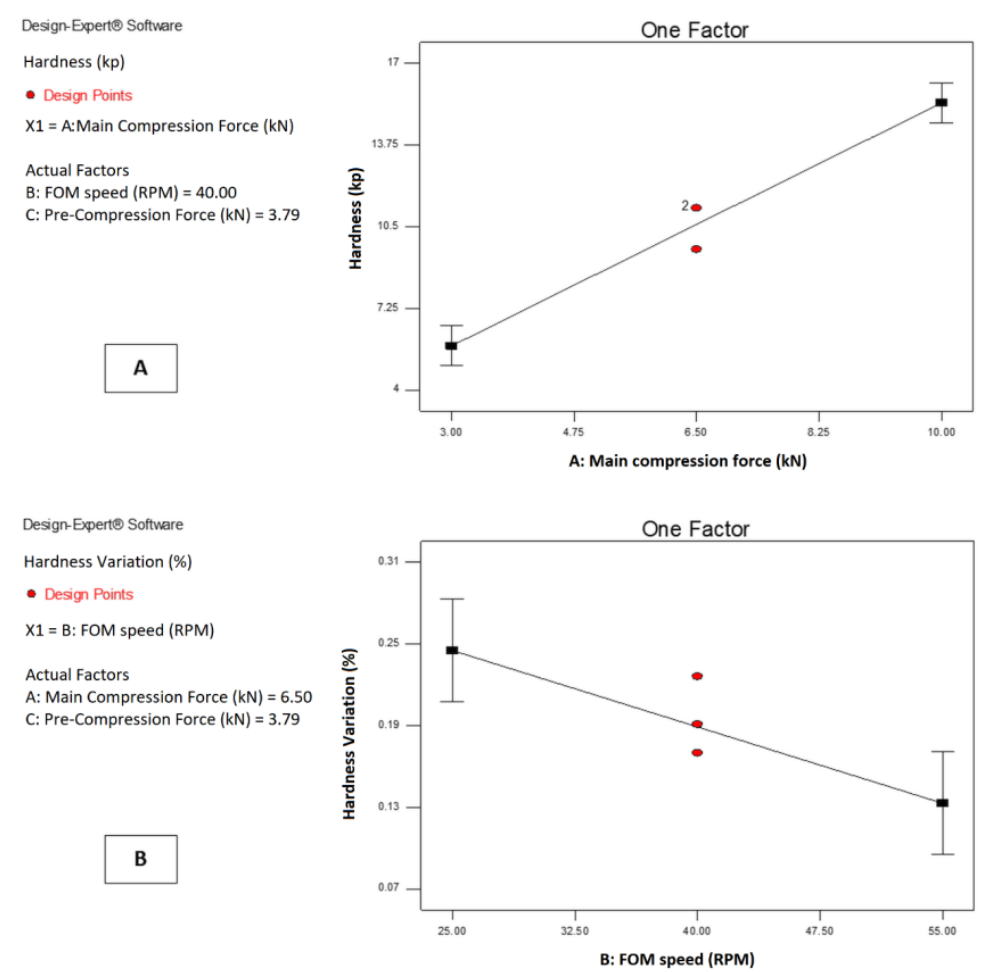

Fig. 2: Effects observed by changing the parameters of the main compression force and FOM speed, in hardness (A) and relative hardness variation (B)

\section{CONCLUSION}

The results of this investigation show that it was possible to apply the Design of Experiment (DoE) methodology in the compression process of the drug Albendazole $400 \mathrm{mg}$ and to assess the impact of the parameters on this tablet production phase. Such knowledge was fundamental for a better understanding of the intrinsic characteristics of our formulation as well as the equipment used. This study showed that the values of the parameters Main Compression Force between 6 to $9 \mathrm{kN}$, Pre-Compression Force from 1.965 to $5.615 \mathrm{kN}$, and $55 \mathrm{RPM}$ of FOM Speed at a compression speed set at 63 RPM, config. a safe and reliable working range for routine production of the product studied, in addition to significantly increasing the productivity since the usual speed of production is about 6 times lower than that tested in this article. The FOM Speed parameter was the main control factor to maintain quality attributes. In a future investigation, the use of alternative tablet press speed ranges and FOM speeds can be studied in order to further optimize the production process.

\section{ACKNOWLEDGEMENT}

The authors are grateful to the Prati-Donaduzzi company for providing the facility to carry out this work.

\section{FUNDING}

Nil

\section{AUTHORS CONTRIBUTIONS}

Lucas da Silva performed experiments, analyzed data, and co-wrote the paper. Emerson Boldo supervised the research and co-wrote the paper.

\section{CONFLICT OF INTERESTS}

The authors declare that there are no conflicts of interest regarding the publication of the paper.

\section{REFERENCES}

1. Aulton ME, Tayloy KMG. The design and manufacture of medicines. $5^{\text {th }}$ ed. New York: Elsevier; 2017.
2. Gamlen M, Tableting G, Domingue J. Tabletting making better tablets: a QbD approach. Tablets and Capsules; 2014. p. 1-6.

3. Tye CK, Sun C, Amidon GE. Evaluation of the effects of tableting speed on the relationships between compaction pressure, tablet tensile strength, and tablet solid fraction. J Pharm Sci 2005;94:465-72.

4. Brazil. RDC ${ }^{\circ} 73$, DOU N ${ }^{\circ} 67$, April 08, 2016. National Health Surveillance Agency-Ministry of Health, Brazil; 2016.

5. ICH. Pharmaceutical Development Q8. ICH Harmonised Tripartite Guideline 2009;8:1-28.

6. Moore CMV. Quality by design-FDA lessons learned and challenges for international harmonization. Int Conf Drug Dev 2012. p. 1-28.

7. S AK, N VG, Dv G, Sivadasu P. Formulation and development of in situ forming gel for the treatment of oral thrush. Asian J Pharm Clin Res 2018;11:342-6.

8. Gupta A, Kumar J, Verma S, Singh H. Application of quality by design approach for the optimization of orodispersible film formulation. Asian J Pharm Clin Res 2018;11:8-11.

9. Guntaka PR, Lankalapalli S. Solubility and dissolution enhancement of ivacaftor tablets by using solid dispersion technique of hot-melt extrusion-a design of experimental approach. Asian J Pharm Clin Res 2019;12:356-63.

10. Khanam N, Alam MI, Md Yusuf Ali QMAI, Siddiqui A. A review on optimization of drug delivery system with experimental designs. Int J Appl Pharm 2018;10:7-12.

11. Chowdary KPR, Shankar KR, Sowjanya VVLSP. Optimization of irbesartan tablet formulation by 23 factorial design. Int J Curr Pharm Sci 2015; 7:39-42.

12. Chaudhary SA. DoE/QbD optimization model for "Tablet compression" process using circumscribed central composite RSM. Int J Pharm 2015;486:1-388.

13. Tho I, Bauer Brand LA. Quality by design (QbD) approaches for the compression step of tableting. Expert Opin Drug Delivery 2011;8:1631-44.

14. Haware RV, Tho I, Bauer Brand LA. Application of multivariate methods to compression behavior evaluation of directly compressible materials. Eur J Pharm Biopharm 2009;72:148-55.

15. Lipps MD, Sakr AM. Characterization of wet granulation process parameters using response surface methodology topspray fluidized bed. J Pharm Sci 1994;83:937-47. 
16. Gonnissen Y, Gonçalves SIV, De Geest BG, Remon JP, Veraet C. Process design applied to optimise a directly compressible powder produced via a continuous manufacturing process. Eur J Pharm Biopharm 2008;68:760-70.

17. Garlapati VK, Roy L. Utilization of response surface methodology for modeling and optimization of tablet compression process. J Young Pharm 2017;9:417-21.

18. Iancu V, Roncea F, Cazacincu RG, Lupu CE, Miresan H, Danaila $\mathrm{CN}$, et al. Response surface methodology for optimization of diclofenac sodium orodispersible tablets (odts). Farmacia 2016;64:210-6.

19. Brunton LL, Knollmen B, Hilal Dandan R. The pharmacological basis of therapeutics. 13 ${ }^{\text {th }}$ ed. New York: McGraw-Hill; 2017.

20. Stat-Ease Design-Expert [software]; 2020. Available from: https://www.statease.com/software/design-expert/ [Last accessed on 18 Nov 2020].

21. Ostertagova E, Ostertag O. Methodology and application of oneway ANOVA. Am J Mech Eng 2013;1:256-61.
22. Brazilian Pharmacopoeia-National Health Surveillance Agency (ANVISA). $5^{\text {th }}$ ed. Brasília; 2010.

23. Khan F, Hossain M, Anika T, Moon SA. Impact of sodium lauryl sulphate on the release of carbamazepine from methocel $\mathrm{k} 15 \mathrm{~m}$ cr based matrix tablets. Bangladesh Pharm J 2012;15:79-82.

24. Masilungan FC, Kraus KF. Determination of precompression and compression force levels to minimize tablet friability using simplex. Drug Dev Ind Pharm 1989;15:1771-8.

25. Chen L, Chen LZ, Yang XJ, Yu YP. Effects of feed shoe wheel speed on tablet weight variability. Key Eng Mater 2012;492:497-500.

26. Peeters E, De Beer T, Vervaet C, Remon JP. Reduction of tablet weight variability by optimizing paddle speed in the forced feeder of a high-speed rotary tablet press. Drug Dev Ind Pharm 2014;41:530-9.

27. Shipar AH, Wadhwa A, Varughese C, Kaur N, Thayaparan N. Effect of compression force on tablet hardness and disintegration time. MT13-3 Toronto Institute Pharm Technol 2014;5:121-9. 